\title{
An Uncommon Early Dermatological Manifestation of Childhood Coeliac Disease
}

Krishna kumar Thattakkat* and Gail Whitehead

Department of Paediatrics, East Cheshire NHS Trust, Macclesfield, UK

\begin{abstract}
Coeliac disease is an autoimmune condition caused by body reaction to gluten. It affects 1:100 people. Common symptoms in children include loose stools, abdominal pain and faltering growth, poor appetite, bloating of abdomen and mood changes. Dermatitis Herpetiformis $(\mathrm{DH})$ is the skin manifestation of coeliac disease affecting 1:3300 people. Most commonly $\mathrm{DH}$ affects people aged 50-69 years and is relatively uncommon in school aged children; especially as an early manifestation of coeliac disease. We present the case of a six year old child who had troublesome persistent itchy blistering rash as the initial manifestation of childhood coeliac disease, that was formally diagnosed several years later, when he developed abdominal symptoms. This is a unique rare presentation in this age group.
\end{abstract}

Keywords: Autoimmune; Appetite; Dermatitis; Coeliac Disease

\section{Background}

We report a 6 year old child who presented with persistent skin rash with blistering and a background history of constipation and iron deficiency anaemia who was confirmed to have coeliac disease. He was being treated for eczema and chronic urticarial with steroids until the diagnosis was confirmed and gluten-free diet was commenced, that resulted in complete resolution of his symptoms, including the troublesome itchy skin rash.

\section{Case Presentation}

A 6 years old boy presented with extensive itchy maculo-papular rash with clusters of itchy blisters distributed symmetrically mainly over his elbows, arms, buttocks and legs (Figures 1-4). This was treated as chronic urticarial with emollients, antihistamines and steroid preparations. The rash continued to get worse and troublesome. He also had background history of chronic constipation requiring treatment with Movicol and past history of Iron deficiency anaemia that improved with haematinics. There was no relevant family history. Weight and height were following the 9th centile; though he has been fussy about

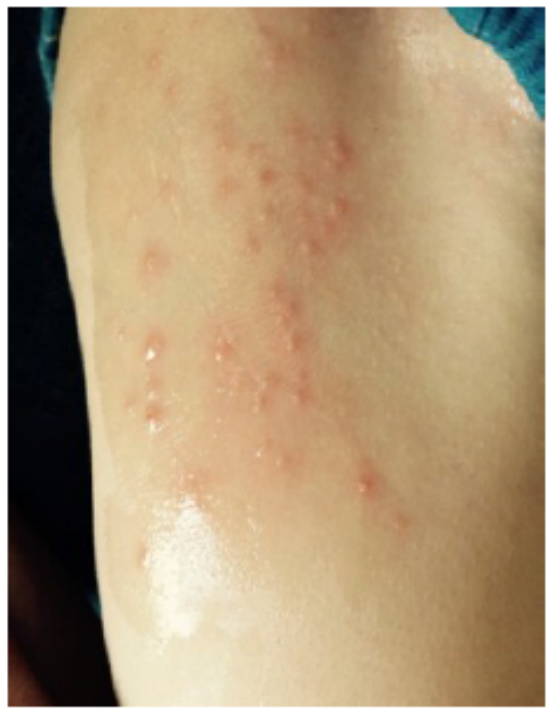

Figure 1: Persistent itchy blistering skin rash over the thigh

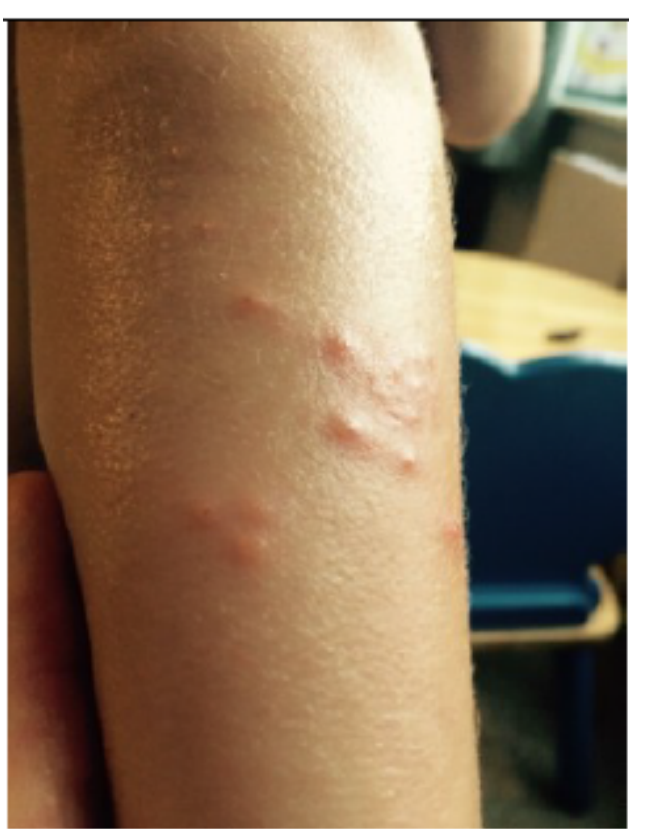

Figure 2: Persistent itchy blistering skin rash over the forearm.

food. Recently he also had started to complain of tummy aches and parents thought his belly appeared more bloated.

\section{Investigations}

When investigated further, IgA tTG level was 119 (normal range less than 4.9). He was also positive for HLA DQ2 genotype. Coeliac disease was thus confirmed as per the NICE (National Institute of

*Corresponding author: Dr. Krishna kumar Thattakkat, Department of Paediatrics, East Cheshire NHS Trust, 18 Home Farm Avenue, Macclesfield, SK10 3QW, UK, E-mail: thattakkat@aol.com

Received June 06, 2018; Accepted June 13, 2018; Published June 18, 2018

Citation: Thattakkat KK, Whitehead G (2018) An Uncommon Early Dermatological Manifestation of Childhood Coeliac Disease. J Health Med Informat 9: 314. doi: 10.4172/2157-7420.1000314

Copyright: (C) 2018 Thattakkat KK, et al. This is an open-access article distributed under the terms of the Creative Commons Attribution License, which permits unrestricted use, distribution, and reproduction in any medium, provided the original author and source are credited. 


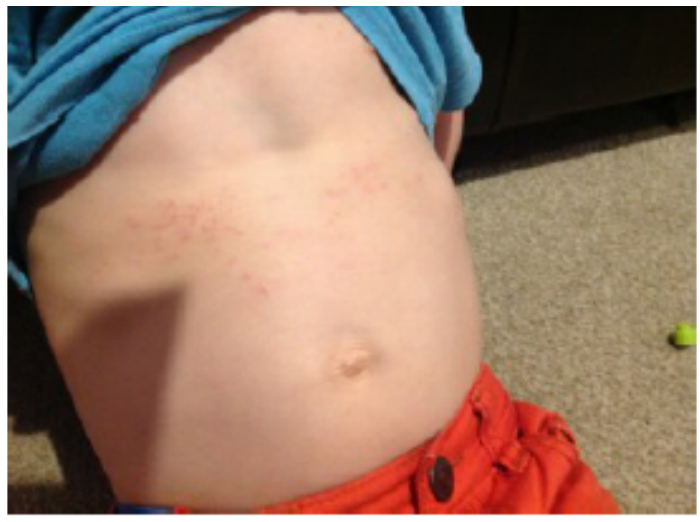

Figure 3: Persistent itchy rash over the abdomen.

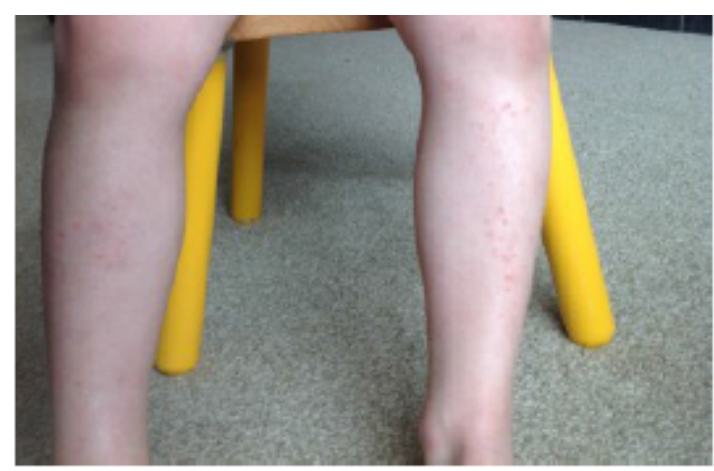

Figure 4: Persistent itchy rash over the legs.

Clinical Excellence, UK) guideline [1]. Other investigations such as full blood count, thyroid function tests, levels of B12, Iron and Folate were normal. He was commenced on gluten free diet. In a year's time, the rash has almost disappeared without any other specific treatment.

\section{Differential Diagnosis}

The rash of DH can be easily mistaken for chronic eczema or urticaria. It is important to think of the differentials especially if the rash is not responding to conventional management.

\section{Treatment}

IgA tTG has now normalised and he continues on gluten free diet.

\section{Outcome and Follow-Up}

We continue to follow him in the joint Paediatric Coeliac clinic.

\section{Discussion}

Coeliac disease is a lifelong auto-immune disorder caused by the abnormal reaction of human body to a protein called gluten present in wheat, barley and rye. The auto antibody causes damage to the small intestine resulting in malabsorptive signs and symptoms that may be difficult to spot. Hence, though a common condition with incidence of $1: 100$, it is estimated that only $24 \%$ of the cases are properly diagnosed [2]. Diagnosis of Coeliac disease in children can be difficult and challenging especially in the absence of classical symptoms like recurrent abdominal pain triggered by ingestion of gluten, loose stools or weight loss. The boy that we report had presented two years ago with constipation. But he was fussy about his diet and was iron deficient. Haemoglobin and
Iron levels normalised with haematinics. He did not have any other significant gastrointestinal symptoms. But over the years, he developed the troublesome itchy blistering skin rash and also had intermittent belly aches, although not specifically related to gluten ingestion. A high index of clinical suspicion helped in establishing the diagnosis of coeliac disease. $\mathrm{DH}$ as a main presenting feature of coeliac disease is very rare in this age group [3]. Exact incidence and prevalence of this presentation is uncertain. There are a few sporadic case reports of such an occurrence; but none from the UK to the best of our knowledge [4,5]. By reporting this case we wish to raise awareness amongst the medical fraternity about childhood coeliac disease and its rare and challenging presentations [610]. All children with persistent blistering itchy skin rash, especially with background history of non-specific gastrointestinal symptoms should be screened for Coeliac disease. Skin biopsy to confirm the dermatological diagnosis of DH is ideally recommended. However in this case although the Consultant Dermatologist clinically agreed with the diagnosis and a further biopsy confirmation was recommended, the parents did not wish to have a biopsy for their child. Moreover the skin rash dramatically improved after the child was commenced on gluten free diet. The general public as well as the primary and secondary care professionals often associate coeliac disease only with gastrointestinal symptoms. This is partly due to their lack of awareness of systemic maifestations of coeliac disease. Being an auto-immune disorder, coeliac disease has protean manifestations, including skin involvement. In a rare case like the one we presented, skin involvement can precede the other symptoms by several years. By presenting this case, we hope to create more awareness and insight amongst the public health as well as acute practitioners regards one of the rare uncommon systemic features of childhood coeliac disease.

\section{Learning Points/Take Home Messages}

- Coeliac disease is often under-diagnosed due to the protean nature of presentation.

- Dermatitis Herpetiformis (DH) is an uncommon presentation of coeliac disease in children.

- DH can be easily mistaken for allergic or urticarial rash.

- DH can commence several years before the actual onset of gastrointestinal symptoms.

\section{Acknowledgement}

We duly acknowledge the secretarial support and patient liaison services provided by Ms Melanie Hodskinson, Paediatric Secretary, during the clinical management of this child as well as preparation of the manuscript.

\section{Conflict of Interest}

The authors declare that there is no conflict of interest regarding the publication of this paper.

\section{References}

1. NICE (2017) Coeliac disease: recognition, assessment and management (NG20). 2015. London: National Institute for Health and Care Excellence.

2. https://www.coeliac.org.uk/coeliac-disease/coeliac-disease-in-children/

3. https://www.coeliac.org.uk/document-library/133-dermatitis-herpetiformis-dh/

4. Templet JT, Welsh JP, Cusack CA (2007) Childhood Dermatitis Herpetiformis: A Case Report and Review of the Literature. Cutis 80: 473-476.

5. Mendes, Fernanda Berti R (2017) Review: Dermatitis Herpetiformis. Anais Brasileiros de Dermatologia 884: 594-599.

6. Hill PG, Holmes GK (2008) Coeliac disease: a biopsy is not always necessary for diagnosis. Aliment Pharmacol Ther 27: 572-577.

7. Dahlbom I, Korponay-Szabó IR, Kovács JB (2010) Prediction of clinical and mucosal severity of coeliac disease and dermatitis herpetiformis by 
Citation: Thattakkat KK, Whitehead G (2018) An Uncommon Early Dermatological Manifestation of Childhood Coeliac Disease. J Health Med Informat 9: 314. doi: 10.4172/2157-7420.1000314

Page 3 of 3

quantification of $\mathrm{lgA} / \mathrm{lgG}$ serum antibodies to tissue transglutaminase. J Pediatr Gastroenterol Nutr 50: 140-146

8. Murch S, Jenkins H, Auth M (2013) Joint BSPGHAN and Coeliac UK guidelines for the diagnosis and management of coeliac disease in children. Arch Dis Child 98: 806-811.
9. Murch S, Stevens R, Sleet S (2014) Diagnosis of Coeliac Disease in Children in Primary Care and Clinical Implications. Br J Gen Pract 625: 382-383.

10. Fasano A, Catassi C (2012) Clinical practice. Celiac disease. N Engl J Med 367: 2419-2426. 